\title{
26
}

\section{The Social in the Virtual}

\author{
Jan Chong, Ingrid Erickson, Kathy J. Lee and Rosanne Siino \\ Center for Work, Technology and Organization \\ Department of Management Science and Engineering \\ Stanford University \\ Stanford, California USA 94305-4024 \\ \{jchong,ierick,kathyjl,rsiino\}@stanford.edu
}

\begin{abstract}
Virtuality is often defined solely as that which lacks or is not material reality, and as such, much of the social order that is uniquely engendered within technologically-mediated realities has been inadequately described. This panel attempts to define virtuality on its own terms, instead of as reality-negative, by showcasing four perspectives of social interaction in virtual space. Panelists Elizabeth Churchill, Thomas Erickson, Cliff Lampe, and Rosanne Siino will share insights into the social orders in the virtualities of their interests. Presentations will be followed by a discussion among panelists and panel participants.
\end{abstract}

\section{Panel Description}

In the last fifteen years it has often seemed that to label something "virtual" was to fully define it. The fact that it was other than "real," in the ways that we understood our physical and material reality, seemed to serve as a sufficient description of its nature. However now, some years on, we can see that this moniker is inappropriately dimensionless, disguising qualities of online environments and computer-mediated activity too simplistically. In an effort to open the 'black box' of virtuality, we contend that virtual environments can be both as complex and as organized as material situations. Like Smith [1], Wellman [2, 3], Turkle [4] and Hinds $[5,6]$, we suggest that online worlds possess multifaceted social patterns and structures that are very much worth studying further.

This panel will explore some of the under-investigated social elements of virtual environments by inviting a set of diverse scholars and practitioners to address the following questions: 
- How are virtual spaces social?

- How do people "come together" in virtual environments?

- How do social presence, influence, and awareness operate in virtual environments?

- Do separate social norms, behaviors, and expectations develop in virtual environments or are they inevitably imported from the material world?

- More broadly, what is the interplay between social patterns and structures in the physical and the virtual?

Each of our invited panelists offers a distinct position from which to answer these queries. Both Rosanne Siino and Cliff Lampe have done extensive empirical investigations of virtual settings. They will bring complementary perspectives to bear on analyses of audio-only teleconference interactions and "massive" online communities, respectively. Tom Erickson and Elizabeth Churchill will not only offer insights from their years in industry, they also pair well in their differing perspectives on social virtual space. Erickson seeks to understand social presence and "virtual" interactions in small groups, while Churchill takes a cultural and anthropological look at larger media spaces.

The structure of the panel will consist of four ten minute presentations and a twenty minute discussion. We will ask each of the panelists to prepare brief comments ahead of time synthesizing their ideas with the other three panelists and will begin the discussion with these statements.

Our ultimate desire in organizing this panel is to provide a deep interrogation of virtual social orders. In particular, we hope to discover whether virtual spaces afford new forms of interaction, and, if so, how these new interaction patterns arise and how they are maintained. In striving toward these goals, we expect to touch on aspects of what it means to be part of a virtual group or community, how agency and identity are expressed virtually, and what is implied by the representation of others in virtual spaces.

\section{Panel Participants}

The following have committed to being participants on this panel:

Elizabeth Churchill, Principal Research Scientist, Yahoo! Research, is currently working on social networking, social computing and social media. A psychologist by training, for the past 15 years she has drawn on diverse areas to consider how to design effective communication situations, both face-to-face and technologicallymediated. Influences on her work include psychology, sociology, anthropology, cultural studies, architecture, and film studies. Her current work considers the augmentation of social spaces with community generated digital content.

Thomas Erickson is a Research Staff Member at the IBM T.J. Watson Research Center. Tom's research involves exploring the design and use of social proxies, minimalist graphical visualizations of people, and activities in online environments. 
He claims that making people and their activities mutually visible to one another enables the social processes (such as imitation, norming, and peer pressure) that make our face-to-face interactions coherent, productive, and engaging, to come into play in online interactions. He has contributed to the design of many products, and authored about 50 publications on topics ranging from personal electronic notebooks and information retrieval systems to pattern languages and virtual community.

Cliff Lampe is Assistant Professor of Telecommunication, Information Studies and Media, Michigan State University. In his research, Cliff works with online communities, including Facebook, Slashdot, SourceForge, and Newstrust. A subset of that interest is the use of recommender and reputation systems to guide massively scaled online interactions. He is the co-author, with Paul Resnick, of "Slash(dot) and burn: distributed moderation in a large online conversation space," which was presented at the Conference on Human Factors in Computing Systems (CHI) in Vienna, Austria in 2004.

Rosanne Siino is a Doctoral Candidate, Center for Work, Technology and Organization, Stanford University. Rosanne's interests center on the socio-emotional effects of digital technologies on how people work. Her two research streams reflect these interests. The first focuses on social interaction patterns and identity implications of geographically distributed group and team work, and the second explores the socio-emotional impact of increasingly autonomous and agent-oriented digital technologies in the workplace-technologies that seemingly make decisions for workers. Rosanne previously spent 16 years in the communications field, serving as Netscape's Vice President of Corporate Communications, from the company's founding until its purchase by AOL.

\section{References}

1. M. Smith and P. Kollock, eds., Communities in Cyberspace: Perspectives on New Forms of Social Organization (Routledge Press, London, 1999).

2. B. Wellman, ed., Networks in the Global Village: Life in Contemporary Communities (Westview Press, Boulder, 1999).

3. B. Wellman, J. Salaff, D. Dimitrova, L. Garton, M. Gulia, and C. Haythornthwaite, Annual Review of Sociology 22, 213-238 (1996).

4. S. Turkle, Life on the Screen: Identity in the Age of the Internet (Simon \& Schuster, New York, 1995).

5. P. Hinds and S. Kiesler, Organization Science 6(4), pp. 373-393 (1995).

6. P. Hinds and S. Kiesler, eds., Distributed Work (MIT Press, Cambridge, 2002).

\section{About the Panel Organizers}

Jan Chong is a PhD Candidate at the Center for Work, Technology \& Organization at Stanford University where she works with Professor Diane Bailey. Jan is interested in knowledge-based aspects of collaboration, particularly in the realm of collaborative software development. Jan has an MS and a BS in Computer Science from Stanford University. 
Ingrid Erickson is a $\mathrm{PhD}$ student at the Center for Work, Technology \& Organization at Stanford University where she works with Professor Diane Bailey. Ingrid is interested in the implications of ubiquitous computing and locative technologies on social practices, new dimensions of place and space, organizational and cultural rhetoric, and interorganizational collaboration. She has conducted research with the Social Computing Group at IBM's T J Watson Research Center and at Boeing's Phantom Works research division. Ingrid has an MS in Information from the School of Information at University of Michigan and an MA in Religious Studies from University of Chicago Divinity School.

Kathy Lee is a PhD student at the Center for Work, Technology \& Organization at Stanford University. Kathy's interested in the new and different ways of sharing/organizing online, and about what these possibilities might mean towards enriching social interaction. More recently, she's also become interested in the design practices that bring these new technologies about within large organizations. Kathy received her MS in Human-Computer Interaction at the University of Michigan and her BS in Mechanical Engineering at MIT.

Rosanne Siino, Doctoral Candidate, Center for Work, Technology and Organization, Stanford University. Please see above. 